\title{
A EDUCAÇÃO AMBIENTAL E GESTÃO DO PROJETO DE ASSENTAMENTO AGROEXTRATIVISTA SÃO FRANCISCO
}

\author{
Luís Geraldo Leão Guimarães ${ }^{1}$ \\ Eduardo José Fernandes Nunes ${ }^{2}$ \\ Avelar Luiz bastos Mutim ${ }^{3}$
}

\begin{abstract}
RESUMO:
O objetivo desse artigo é refletir sobre a relação entre a Educação Ambiental e a Gestão no Projeto de Assentamento Agroextrativista São Francisco, enfocando as possibilidades de construção de uma gestão para a sustentabilidade através das contribuições de uma educação ambiental transformadora. Partimos da contextualização do projeto, da sua história, de seus moradores, incluindo também o Movimento CETA que coordena/assessora o assentamento, do dilema entre produzir e preservar enfrentado no dia a dia pelos assentados/as, para, em seguida discutir sobre Educação Ambiental e sobre Gestão buscando compreender as possibilidades de contribuição para o processo de autogestão do projeto.
\end{abstract}

Palavras-chave: Educação Ambiental; Gestão; Assentamento Agroextrativista.

RESUMEN: El objetivo de este artículo es reflexionar sobre la relación entre la Educación Ambiental y la Gestión en el Proyecto de Asentamiento Agroextrativista San Francisco, enfocando las posibilidades de construcción de una gestión para la sostenibilidad a través de las contribuciones de una educación ambiental transformadora. Partimos de la contextualización del proyecto, de su historia, de sus habitantes, incluyendo también el Movimiento CETA que coordina / asesora el asentamiento, del dilema entre producir y preservar enfrentado en el día a día por los asentados, para luego discutir sobre Educación Ambiental Y sobre Gestión buscando comprender las posibilidades de contribución al proceso de autogestión del proyecto.

Palabras clave: Educación ambiental; Gestión; Asentamiento Agroextrativista

\section{CONHECENDO O CENÁRIO, OS SUJEITOS E O PROBLEMA}

\footnotetext{
1 Doutorando do Programa de Pós-Graduação em Educação e Contemporaneidade/UNEB luisppgeduc@gmail.com

${ }^{2}$ Doutorado em Análise Geográfica Regional pela Universidade de Barcelona. Mestrado em Ciências Sociais pela Universidade Federal da Bahia (UFBA). Graduado em Ciências Sociais (UFBA) e Professor do PPGEduC/UNEB. Email: eduardojosf2@gmail.com

${ }^{3}$ Doutorado em Educação pela Universidade Federal da Bahia (UFBA). Mestrado em Educação pela Universidade Federal da Bahia (UFBA). Graduado em Ciências Agrárias pela Universidade do Estado da Bahia (UNEB). Professor Titular Permanente do PPGEduC/UNEB. E-mail amutim@ hotmail.com
} 
A preocupação com essa temática de estudo surgiu da minha experiência com o tema, desde os anos 80 do século passado como extensionista rural (Técnico Rural Nível Médio) da Empresa de Assistência Técnica e Extensão Rural da Bahia (EMATER-BA), trabalhando com agricultores/as familiares e suas organizações e passo a buscar caminhos alternativos para os problemas enfrentados por eles, como a diversificação da produção, o cultivo consorciado de plantas, o uso de inseticidas naturais, o controle biológico de pragas, o associativismo/ cooperativismo, entre outros. Tendo então contato com a chamada "agricultura alternativa" que proponha uma relação mais harmônica com o meio ambiente. Depois, no final dos anos 90 do sec. $\mathrm{XX}$, como aluno do curso de pedagogia do Departamento de Ciências Humanas e Tecnologias (DCHT), Campus XVII, em Bom Jesus da Lapa, participando das discussões com grupos locais sobre educação ambiental, sendo por isso indicado para representar o DCHT no Conselho Municipal de Defesa do Meio Ambiente (COMDEMA) de Bom Jesus da Lapa, o que me motivou, no curso de pósgraduação, a pesquisar e escrever sobre Educação Ambiental (EA).

Há um consenso sobre a importância da EA para a preservação da vida no planeta Terra, conforme pensam Waldman (2001), Medina e Santos (2001), Carvalho (2002), Saito (2002), Loureiro (2004, 2011), Lima (2011), Mutim (2007), entre outros, pois só através da mudança de atitudes e valores é que será possível "rever" a nossa relação com a natureza e com os outros homens, criando uma sociedade ambientalmente equilibrada e socialmente justa (pautada na sustentabilidade). E essa mudança só é possível via processos educativos tanto formais (escolas, universidades, etc.), como não-formais (Sindicatos, ONG, Movimentos sociais, etc.). Parafraseando Paulo Freire (2000), podemos afirmar que se a EA não muda o mundo, também o mundo não muda sem a EA.

O Projeto de Assentamento Agroextrativista São Francisco (PAE-SF) fica localizado na margem esquerda do rio São Francisco nos municípios baianos de Serra do Ramalho e Carinhanha, numa Área de Preservação Permanente (APP), e teve como objetivo principal a regularização fundiária das populações tradicionais de pescadores/agricultores que viviam nessa região nas áreas de reserva do Projeto Especial de Colonização - Serra do Ramalho (PEC/SR), implementado pelo governo federal para alojar a população atingida pela construção da barragem de Sobradinho, na década de 70 do século passado.

Segundo Sodré (2008), os/as assentados/as do PAE-SF são, em sua maioria, descendentes dos moradores das antigas fazendas situadas às margens do rio São Francisco, formada por pescadores artesanais, vaqueiros, agregados e agricultores familiares que, Revista Educação e Ciências Sociais, Salvador, v.1, n.1, 2018. 
habitantes/moradores de uma APP tem que conciliar as atividades econômicas com a preservação ambiental, criando, na maioria das vezes, conflitos entre a própria sobrevivência (e da família) com a preservação dos recursos naturais.

O PAE-SF foi criado pela Portaria INCRA/SR-05/Nº62 de 27 de novembro de 1995 (BRASIL, 2001), e por estar localizado numa APP, constitui como um exemplo de reforma agrária ecológica. Ocupa uma área de 20.820 hectares, sendo formado por 11 comunidades, onde moram 600 famílias legalmente assentadas e outras 200 de forma irregular (não assentadas por vários motivos: forasteiros, "sem perfill", entre outros)

O PAE-SF é ocupado por uma população tradicional de ribeirinhos (pescadores artesanais/agricultores familiares), que segundo Sodré (op.cit. p. 88) “[...] se orienta por normas passadas entre gerações para a utilização dos recursos da natureza, de tal forma que não percebe que algumas destas são práticas predatórias.” Por outro lado Sodré (op.cit. p.237) salienta que "o saber que essas famílias adquiriram sobre o meio ambiente decorre da sua relação constante com ele e, portanto, a forma de preservá-lo vem, sobretudo, da necessidade de mantê-lo para a sua própria sobrevivência e ainda para seus sucessores" facilitando um provável trabalho com educação ambiental, pois, segundo a autora, para o camponês a

(...) natureza não significa simplesmente algo que está ao seu redor, mas é, acima de tudo, o local com que ele interage, lugar de vida e de trabalho: constitui uma visão de mundo. No PAE-SF, a relação homem-natureza é resultado de uma história construída ao longo de muitas gerações (SODRÉ, 2008. p.287).

A criação do PAE-SF foi uma conquista da população local apoiada inicialmente pela Comissão Pastoral da Terra $(\mathrm{CPT})^{4}$ e depois pelo Movimento CETA, que é um movimento social que luta por reforma agrária, coordena vários acampamentos e assentamentos de reforma agrária na Bahia e em Sergipe, sendo o responsável pela coordenação do PAE-SF.

O Movimento CETA surgiu em 1994, em função do grande número de conflitos fundiários na Bahia e das dificuldades encontradas pelos trabalhadores/as no acesso à terra, inicialmente como Coordenação Estadual dos Trabalhadores/as Acampados/as e Assentados/as, daí a origem da sigla CETA. Após um processo de amadurecimento e

\footnotetext{
${ }^{4}$ A Comissão pastoral da Terra é uma entidade católica, que atua junto aos trabalhadores/trabalhadoras do campo, articulando-se com diversas entidades e organizações dos camponeses e com outras entidades e organizações que apoiam suas lutas e reivindicações (SODRÉ, 2008. p. 93).
}

Revista Educação e Ciências Sociais, Salvador, v.1, n.1, 2018. 
disseminação das lutas, em 2002 tornou-se um Movimento, ampliando a sua forma de atuação e manteve o nome original - Movimento CETA ${ }^{5}$.

Organizado no estado da Bahia, com sete regionais (Lapa; Médio São Francisco; Sertão; Chapada; Sul; Sudoeste e Recôncavo Baiano), tem pretensão de expandir a atuação para outros estados brasileiros. Atualmente o CETA possui 3.123 famílias acampadas e 10.247 famílias assentadas. Segundo Bartolomeu, um dos coordenadores do Movimento, (apud MOREIRA, 2010. p.71) o momento de reconhecimento público da força do movimento foi com a "marcha pela terra" em abril de 2003, quando os militantes ficaram acampados por mais de 15 dias em Salvador, desenvolvendo suas pautas de reivindicações. O Movimento afirma ter por objetivos:

[A] luta pela terra e por Reforma Agrária justa, capaz de dar condições de sustentabilidade, comercialização, lazer, formação e emancipação aos trabalhadores/as rurais, tendo como princípios o respeito à democracia, ao meio ambiente e relações equitativas de gênero, raciais e de geração (CETA, 2013)

Embora tenha origem na luta pela terra, o Movimento dos Trabalhadores/as Assentados/as, Acampados/as e Quilombolas - CETA, conforme Moreira (2010), incorpora como missão a preservação ambiental e uma educação contextualizada, o que por si só já o qualifica para dirigir a luta dos ribeirinhos/as assentados/as do Projeto de Assentamento Agroextrativista São Francisco, configurando segundo Viola (1991, apud DIEGUES, 2001, p.130), um "ambientalismo camponês, que luta por manter acesso aos recursos naturais de seus territórios, valoriza o extrativismo, os sistemas de produção baseados em tecnologias alternativas."

O Movimento CETA e os/as assentados vivem o dilema de preservar a natureza do PAE-SF e de produzir a própria existência, ou seja, o de produzir e preservar. Que pode ser equacionado a partir da maneira que eles (assentados/as e Movimento CETA) efetivam a gestão do assentamento. Que soluções tem encontrado o Movimento CETA e os/as assentados/as para resolver esse dilema? Como tem sido discutidas, formuladas e implementadas as prováveis soluções? Todas essas questões são potencializadas por processos de educação ambiental que possibilitam "análises" mais pertinentes da realidade vivida e percebida pelos envolvidos no processo e consequentemente formas sustentáveis de gestão do PAE-SF.

Esse artigo busca contribuir na reflexão sobre as possíveis soluções para os problemas socioambientais enfrentados pelos ribeirinhos/as assentados/as no PAE-SF que

\footnotetext{
${ }^{5}$ Dados disponíveis em: www.cetabahia.blogspot.com.br Acesso em 04/10/2013.

Revista Educação e Ciências Sociais, Salvador, v.1, n.1, 2018.
} 
vivem o dilema entre produzir sua existência ou preservar o ambiente, e com o Movimento CETA, responsável pela organização das lutas sociais dessa população tradicional, que precisa resolver este dilema, encontrando/construindo formas sustentáveis de produzir conservando os recursos naturais.

Partindo do pressuposto defendido por Nunes; Mutim; Costa (2014, p.459) de que "a Educação Ambiental se impõem como uma necessidade na construção de um sistema de gestão compartilhada das políticas públicas," objetiva, também, o desenvolvimento/produção de conhecimentos específicos relacionados à contribuição da EA para a gestão em assentamentos da chamada "reforma agrária ecológica" (SODRE, 2008) nas condições do semiárido nordestino, em particular, em Serra do Ramalho-Bahia. Buscando assim contribuir para articular os envolvidos nos processos de gestão, no sentido de estimular reflexões, debates e inquietações sobre as possíveis alternativas para enfrentar os problemas socioambientais vividos pelos assentados/as.

\section{DISCUTINDO EDUCAÇÃO AMBIENTAL E GESTÃO}

\subsection{Educação Ambiental}

Conceituar Educação Ambiental (EA) é muito complexo, para explicitar o que é e qual sua importância, Carvalho (2002) adota a definição formulada na Conferência da UNESCO de Educação Ambiental realizada em Chosica - Peru em 1976, como a que mais se aproxima daquilo que ele entende por Educação Ambiental:

Educação Ambiental é ação educativa permanente pela qual a comunidade educativa tende à tomada de consciência de sua realidade global, do tipo de relações que os homens estabelecem entre si e com a natureza, dos problemas derivados destas relações. (UNESCO Apud CARVALHO, 2002. p. 51)

Carvalho defende a ideia que toda educação é ambiental, pois o processo educativo é realizado num "meio" que é o ambiente dos sujeitos da educação que vivem e convivem nesse ambiente com outros seres vivos e que para sobreviverem estabelecem relações amplas com o meio. Portanto, o "adjetivo 'ambiental' (...) ao lado do substantivo 'educação' serve a meu ver, apenas para reforçar dimensões que já estão contidas no mesmo; não devendo portanto, existir limites rígidos entre os conceitos de Educação e Educação Ambiental" (CARVALHO, ibid. p.36), ressaltando porém que devido à crise ambiental e a própria crise da modernidade há a necessidade de demarcar a especificidade da dimensão ambiental como resgate da totalidade do processo educativo rompendo com a compartimentação e fragmentação próprias do paradigma cartesiano.

Revista Educação e Ciências Sociais, Salvador, v.1, n.1, 2018. 
Para Medina e Santos (2001), Educação Ambiental não se trata tão-somente de ensinar sobre a natureza, mas de educar "para" e "com" a natureza; para compreender e agir corretamente ante os grandes problemas das relações do homem com o ambiente. Para elas EA “é a incorporação de critérios sócio-ambientais, ecológicos, éticos e estéticos nos objetivos didáticos da educação" (ibid. p. 25). Loureiro (2011) sintetiza e amplia o conceito de EA como "uma práxis educativa e social que tem por finalidade a construção de valores, conceitos, habilidades e atitudes que possibilitem o entendimento da realidade de vida e a atuação lúdica e responsável de atores sociais individuais e coletivos no ambiente." (op. cit. p. 73).

Nesse sentido, Saito (2002), fala em quatro grandes desafios da EA que são: buscar uma sociedade democrática e socialmente justa; desvelar as condições de opressão social; praticar uma ação transformadora intencional e por fim, promover a contínua busca do conhecimento. Reafirmando que a resolução desses desafios constitui um "caminho para estabelecermos uma sociedade ambientalmente mais equilibrada, juntamente com uma sociedade mais justa, mais igualitária e efetivamente mais democrática" (ibid. p. 58).

Não se discute mais a importância da EA para a melhoria da chamada "qualidade de vida" na nossa sociedade. Todos (educadores, administradores, sociedade civil e política) concordam que é imperativo mudar o nosso comportamento em relação ao meio ambiente. $\mathrm{O}$ problema e a grande polêmica é como efetivamente desenvolver uma EA que dê conta de "mudar" a mentalidade das pessoas, alterando aspectos culturais e de comportamento, que por si só não garantem a resolução dos problemas ambientais, pois os mesmos derivam da forma como a sociedade está organizada e de como se dá a apropriação dos recursos naturais (o sistema de produção).

Diretamente todos ou quase todos os problemas ambientais estão relacionados com a apropriação dos bens naturais e numa sociedade capitalista há o agravante dessa apropriação ser privada, o que aliás é a essência dessa sociedade, com a consequente socialização coletiva dos desequilíbrios ambientais (seca, enchentes, erosão do solo, poluição do ar e das águas, fome, etc.), onde a maioria da população arca com os prejuízos e as elites se locupletam das benesses, das riquezas.

Por esse prisma, fica evidente que para as elites não é interessante "mudar" a mentalidade das pessoas no que tange às nossas relações com a natureza - fonte primária da riqueza e da nossa humanização.

Historicamente as elites (classes dominantes) detiveram o controle da sociedade e a consequente imposição de suas ideias e valores (a ideologia), mas havendo contudo, Revista Educação e Ciências Sociais, Salvador, v.1, n.1, 2018. 
resistência dos oprimidos (classes dominadas) que lutam desesperadamente para conseguirem sobreviver livres do jugo opressor. Assim, a questão ambiental (resultante da apropriação privada da natureza) está no centro da luta de classe e portanto numa disputa ferrenha, pois questionar as agressões ao meio ambiente é questionar a sua apropriação (direta ou indireta) pelo capital.

Preocupados com essa disputa, a classe dominante ou setores dela, criaram o ecocapitalismo ${ }^{6}$, que segundo Waldman (2001, p. 30):

\begin{abstract}
Ao não questionar formas de produção, paradigmas econômicos e modelo de consumo, legitimam [e criam] o Consumismo Verde ${ }^{7}$. (...). Para os ecocapitalistas a defesa da ecologia passa pela fabricação de carros que "poluam menos" e não pela defesa de meios alternativos de transporte (como as ciclovias) ou a melhoria do transporte público. Propõe métodos de reciclagem e recuperação de matériasprimas, mas não produtos com maior coeficiente de durabilidade, e assim por diante. (...) Embora discordando da depredação ambiental, não questionam os valores e as relações de poder existentes no interior desta mesma sociedade.
\end{abstract}

Em suma, é a manutenção da apropriação privada da natureza e a consequente pilhagem e destruição da mesma. Nesse sentido, o capitalismo num "toque do Rei Midas", da mitologia grega, transforma um grande problema em mais uma fonte de lucros, pois "a água, o solo, o 'verde' entre outros elementos, a partir do momento que são contaminados, poluídos e depredados, justificam sua transformação em bens adquiridos em mercado." (WALDMAN, 2001, p.19).

Pelo exposto até aqui, fica claro que é muito difícil, nos marcos do capitalismo, propor ou montar um currículo que de fato trabalhe a EA na profundidade que se faz necessária para efetivamente "mudar" a mentalidade das pessoas, pois implica mudar o próprio sistema com seus valores, ideias e costumes. Por outro lado, é possível (e desejável) aproveitar as contradições inerentes do capitalismo e construir contra-ideologicamente, no sentido gramsciano da palavra, a educação ambiental transformadora, irmã, eu diria, das pedagogias críticas, tributárias das lutas emancipatórias dos oprimidos do mundo. Reafirmo que nós (educadores), não podemos "cruzar os braços" diante das questões ambientais face às dificuldades impostas pelo sistema, é preciso e urgente saber conjugar luta política e luta ecológica, pois uma está implicada na outra numa relação profundamente dialética.

\footnotetext{
${ }^{6}$ Conceito derivado da corrente ecológica denominada ecocapitalista, que acreditam que a economia de mercado é a única a regular eficientemente a relação homem/natureza (WALDMAN, 2001, p.32)

${ }^{7}$ Vertente ecológica do consumismo capitalista, que exploram o apelo emocional das questões ambientais nos consumidores para venderem seus produtos.

${ }^{8}$ Rei Midas personagem da mitologia grega que transforma em ouro tudo o que toca com as mãos. (BRANDÃO, 2000, p.122).

Revista Educação e Ciências Sociais, Salvador, v.1, n.1, 2018.
} 
A EA encontra-se mais desenvolvida na modalidade de educação não-formal que é onde encontramos o maior número de experiências e diversidade de ações, até mesmo as desenvolvidas pelo poder público como é o caso dos cursos de capacitação em educação ambiental promovidos pelos órgãos do Ministério do Meio Ambiente e pelo Centro de Recursos Ambientais (CRA), este vinculado à Secretaria do Planejamento, Ciência e Tecnologia da Bahia, só para ficar com dois exemplos um federal e outro estadual.

Mas o grande impulso da EA no Brasil se deve às iniciativas das Organizações Não Governamentais, principalmente as denominadas ONGs Verdes que perceberam que a mudança de mentalidade das comunidades só seria possível através de um processo educativo que despertasse a "consciência ecológica" das populações diretamente envolvidas com os problemas ambientais e propiciasse a busca de soluções para os mesmos.

Lima (2004) classifica a EA em duas polaridades, uma conservadora e a outra emancipatória, a primeira "se interessa pela conservação da atual estrutura social, com todas as suas características e valores econômicos, políticos, éticos e culturais" (op.cit. p. 132), e a segunda pelo "compromisso de transformação da ordem social vigente, de renovação plural da sociedade e de sua relação com o meio ambiente" (ibid. p.132). Entre essas duas polaridades o autor aponta ainda uma terceira categoria denominada de conservadorismo dinâmico que atua para desviar o rumo transformador/mobilizador das lutas pelas questões ambientais, operando "por mudanças aparentes e parciais nas relações sociais e nas relações entre a sociedade e o ambiente enquanto conserva o essencial" (ibid. p.132), sendo a com maior visibilidade na mídia e apoio dos governos e empresas, constituindo-se, segundo o autor, o mais poderoso obstáculo para uma abordagem transformadora dos problemas ambientais.

Nesse sentido, Loureiro (2011) aponta a necessidade da construção da ecocidadania/cidadania planetária como a inclusão de uma ética ecológica no cotidiano das nossas vidas, possibilitando a formação da consciência individual e coletiva das nossas responsabilidades locais/comunitárias/globais (planetária) para com o respeito à vida. E para ele é imprescindível a "construção de estratégias dialeticamente locais e globais, comunitárias e governamentais, instrumentais e educativas, que cumpram a mediação entre as esferas econômicas e político-cultural e apontem para um ambientalismo comprometido com as lutas sociais e populares" (op. cit. p. 84).

A educação (formal e não formal) e os educadores, principalmente os ambientais, tem um importante papel a desempenhar na construção de uma sociedade sustentável, pois como afirmam Silva e Déjardin (2011, p.175)

Revista Educação e Ciências Sociais, Salvador, v.1, n.1, 2018. 
(...) a educação numa perspectiva de sustentabilidade pressupõe a imersão do sujeito em seu contexto social e a sensibilidade deste para as questões complexas da atualidade, dentre as quais as de cunho ambiental, social, cultural e econômico. (...) Entendemos a educação como via direta de ampliação da consciência das pessoas nas suas relações com os outros, com a vida comunitária e com a natureza.

E nesse sentido Nunes; Mutim e Costa (2014, p.459) enfatizam que:

\begin{abstract}
A diversidade socioambiental dessas duas importantes regiões brasileira [Norte e Nordeste - onde se localiza o PAE-SF] e os conflitos ambientais gerados favorece e demanda uma atenção especial no sentido da construção de um sistema de gestão capaz de viabilizar a participação da população na busca de ações que minimizem os problemas.
\end{abstract}

\title{
2.2 Gestão do assentamento
}

Os assentados/as do PAE-SF “estão organizados de forma coletiva, na Central das Associações dos Moradores (CAM) que é responsável pela gestão de todo o projeto" (BRASIL. 2001, p. 7). Em cada uma das onze comunidades existentes, os assentados participam de uma Associação de Moradores, que por sua vez indica/elege três representantes para compor a diretoria da CAM do PAE - SF, que tem a responsabilidade pela execução do plano de utilização e para isso “designará GRUPOS e EQUIPES DE TRABALHO para atuarem nas distintas áreas da execução administrativa - operacional do projeto e responder solidariamente pelo mesmo" (Ibidem, p. 13).

No plano de utilização é recomendado que o PAE-SF seja administrado na forma de autogestão, sendo os moradores, na qualidade de coautores e cogestores da administração, responsáveis de forma coletiva ou individual pela execução do mesmo.

Mas como tem sido efetivada a gestão do PAE-SF? Qual o significado do termo gestão para os assentados/as? As respostas a essas indagações nos leva a questionar/problematizar sobre o que de fato seja gestão, administração, autogestão.

O conceito administração é muito relacionado ao mundo dos negócios, à área empresarial e por isso tem uma conotação técnico-racional pautada na eficiência, objetividade, hierarquia, disciplina e lucratividade. Segundo Luck (2010. p.57) a "administração é vista como um processo racional, linear e fragmentado de organização e de influência estabelecida de cima para baixo e de fora para dentro das unidades de ação", que tem uma forma mecanicista e utilitária de utilizar pessoas e recursos, os mais diversos, para alcançar os objetivos previstos. Nesse sentido, o ato de administrar é caracterizado como comando e controle. Não sendo nessa perspectiva, adequado para designar ações de caráter coletivos em instituição/movimentos sociais, que requer na visão de Luck (2010, p. 57)

Revista Educação e Ciências Sociais, Salvador, v.1, n.1, 2018. 
[...] a participação ativa de todos os envolvidos em uma unidade social, para tomada de decisão conjunta, mediante processo de planejamento participativo pelo qual a realidade é analisada pela incorporação de diferentes olhares que, ao serem levados em consideração, permitem que as decisões tomadas o sejam a partir de uma visão abrangente das perspectivas de intervenção, além de garantirem o comprometimento coletivo com a implementação do planejado.

Configurando como um processo de gestão (grifo nosso) que, segundo Luck (op.cit.) possui uma lógica pautada por princípios democráticos centrados no reconhecimento da primazia da participação consciente e autônoma das pessoas na tomada de decisões sobre os rumos a serem seguidos, na organização e no planejamento necessário ao seu trabalho. Para a autora (id. 2009, p. 21) a gestão é "um processo de mobilização da competência e da energia de pessoas coletivamente organizada para que, por sua participação ativa e competente, promovam a realização, o mais plenamente possível, dos objetivos da sua unidade de trabalho".

A autogestão aparece quando os trabalhadores percebem que a sua organização é uma tarefa para eles próprios (COSTA; OLIVEIRA; MELO NETO, 2006), e se configura como a tomada da consciência histórica de que somos construtores do nosso próprio destino, da nossa própria história. Esse processo pressupõem a mais ampla participação, autonomia, democracia, cooperação, autoanálise, diálogo e educação, pois segundo Motta (1981, apud. COSTA; OLIVEIRA; MELO NETO, op.cit. p. 65) "A sociedade autogestionária é a sociedade organicamente autônoma, constituída de um feixe de autonomias, de grupos se auto-administrando, cuja vida exige a coordenação, mas não a hierarquização", onde todos são, individual e coletivamente, responsáveis pela gestão da comunidade/organização desde o planejamento até a execução final de todas as atividades do grupo.

Pelo exposto até aqui, fica evidente que a decisão adotada no Plano de Utilização do PAE - SF (BRASIL, 2001) de recomendar a gestão do Projeto na forma de autogestão é a mais coerente com a finalidade proposta de promover o desenvolvimento local por meio de uma ação transformadora com bases sustentáveis, que leve em consideração a tradição e a cultura dos assentados/as.

Costa; Oliveira e Melo Neto (2006, p. 84) chamam a atenção para a importância da educação nos processos de autogestão, pois é necessária uma constante aprendizagem de "conhecimentos de novas formas de se poder viver que não apenas as estabelecidas nos marcos das relações capitalistas”. Mutim (2007. p.115) ampliando para a educação ambiental, compartilha dessa mesma visão ao afirmar que:

Revista Educação e Ciências Sociais, Salvador, v.1, n.1, 2018. 
A Educação Ambiental como articulação sistêmica dos processos educativos formais e não formais é parte vital e indispensável para se chegar ao desenvolvimento local e à gestão de sociedades sustentáveis, pois é a maneira mais direta e funcional de se atingir objetivamente a meta da participação dos indivíduos e das comunidades locais/territoriais na tomada de decisão a respeito do patrimônio socioambiental

Dowbor (2014, p.1) reforça a importância da educação para o desenvolvimento local ao postular que a mesma quando a serviço da comunidade local "devolve ao cidadão a compreensão de que pode tomar o seu destino em suas mãos, conquanto haja uma dinâmica social local que facilite o processo, gerando sinergia entre diversos esforços." E que "podemos ser donos da nossa própria transformação econômica e social, de que o desenvolvimento não se espera mas se faz." Pois afinal a "ideia da educação para o desenvolvimento local está diretamente vinculada a esta compreensão, e à necessidade de se formar pessoas que amanhã possam participar de forma ativa das iniciativas capazes de transformar o seu entorno, de gerar dinâmicas construtivas."

Pelo exposto até aqui, fica evidente que a decisão adotada no Plano de Utilização do PAE - SF (BRASIL, 2001) de recomendar a gestão do Projeto na forma de autogestão é a mais coerente com a finalidade proposta de promover o desenvolvimento local por meio de uma ação transformadora com bases sustentáveis, que leve em consideração a tradição e a cultura dos assentados/as.

\section{CONSIDERAÇÕES FINAIS}

Fica claro que a resolução do dilema vivido pelos assentados/as do PAE -SF de "preservar ou produzir" só pode encontrar soluções dentro de um sistema de gestão dialógica e participativa na forma de autogestão, mas para isso se torna imprescindível a contribuição da Educação Ambiental. Que assim, numa perspectiva transformadora, pode contribuir para a gestão, na sua forma autogestionária, ao possibilitar a compreensão ampla: das relações sociais na sociedade capitalista; da ampliação da participação da comunidade na gestão (MUTIM, 2007); da formação de uma cidadania ecológica/planetária (LOUREIRO, 2011); da materialização de possibilidades de ação no plano local a partir dos conhecimentos gerais (DOWBOR, 2014); e, uma compreensão do nosso lugar no mundo, na cultura e na natureza.

Afinal somos todos responsáveis pela construção de sociedades sustentáveis. Que passa por pela valorização do território e de todos os recursos ali existentes (naturais, humanos, econômicos, institucionais e culturais), e que vão constituir o enorme potencial de

Revista Educação e Ciências Sociais, Salvador, v.1, n.1, 2018. 
melhoria da qualidade de vida para todos. Sendo necessário e urgente conhecer em profundidade este potencial, para construir uma modalidade de desenvolvimento sustentável com as características local/regional/planetária. Possibilitando assim as transformações sociais almejadas por todos/as que lutam por uma sociedade mais igualitária, socialmente justa e ambientalmente equilibrada.

\section{REFERÊNCIAS}

ANDRADE, Maria margarida de. Introdução à metodologia do trabalho científico. 6 . ed. São Paulo: Atlas, 2003.

BRASIL, Ministério do Desenvolvimento Agrário - MDA/Instituto Nacional de Reforma Agrária - INCRA. Plano de utilização do Projeto de Assentamento Agroextrativista São Francisco. Brasília: Guarany, 2001.

BRANDÃO, Junito. Dicionário Mítico-etimológico. vol. II, 3. ed. Petrópolis: Vozes, 2000.

CARVALHO, Vilson Sérgio de. Educação ambiental \& desenvolvimento comunitário. Rio de Janeiro: Wak, 2002.

CETA. Breve histórico do Movimento. Disponível em:〈www.cetabahia.blogspot.com.br> Acesso em 04/10/2013

COSTA, Francisco Xavier Pereira da; OLIVEIRA, Iolanda Carvalho de; MELO NETO, José Francisco de. Incubação de empreendimento solidário popular: fragmentos teóricos. João Pessoa - PB: Editora Universitária/UFPB, 2006. p. 46 - 92.

DIEGUES, Antônio Carlos Santana. O mito moderno da natureza intocada. 3.ed. São Paulo: Hucitec, 2001.

DOWBOR, Ladislau. Educação e desenvolvimento local. Disponível em <http://www. apodesc.org/sites/documentos_estudos/arquivos/Desenvolvimento_EDUCACAO_E_DESE N VOLVIMENTO_LOCAL_Ladislau\%20Dowbor.pdf>. Acesso em: 26/04/2014.

FREIRE, Paulo. Pedagogia do oprimido. 29. ed. Rio de Janeiro: Paz e Terra, 2000.

LIMA, Gustavo F. da Costa. Crise ambiental, educação e cidadania: os desafios da sustentabilidade emancipatória. In: LOUREIRO, Carlos F. Bernardo; LAYRARQUES, Philippe Pomier; CASTRO, Ronaldo Souza de. (orgs.) Educação ambiental: repensando o espaço da cidadania. 5.ed. São Paulo: Cortez, 2011. p. 115 - 148.

LOUREIRO, Carlos F. Bernardo. Educação ambiental e movimentos sociais na construção da cidadania ecológica e planetária. In: LOUREIRO, Carlos F. Bernardo; LAYRARQUES, Philippe Pomier; CASTRO, Ronaldo Souza de (orgs.) Educação ambiental: repensando o espaço da cidadania. 5.ed. São Paulo: Cortez, 2011. p. 73 - 103. 
- Educação ambiental transformadora. In: LAYRARQUES, Philippe Pomier. (coord.) Identidades da educação ambiental brasileira. Brasília: Ministério do Meio Ambiente, 2004. p. $65-84$.

LUCK, Heloísa. Gestão educacional: uma questão paradigmática. 5.ed. Petrópolis: Vozes, 2010.

A gestão participativa na escola. 5.ed. Petrópolis: Vozes, 2009.

MEDINA, Naná Mininni; SANTOS, E. da Conceição. Educação ambiental: uma proposta participativa de formação. 2 ed. Petrópolis -RJ.: Vozes, 2001

MOREIRA, Edna Souza. A licenciatura de Pedagogia da Terra: uma proposta de formação para o educador do campo. 2010. 114f. Dissertação (Mestrado em Educação). Universidade do Estado da Bahia, Salvador. 2011.

MUTIM, Avelar Luiz Bastos. Educação ambiental e gestão de sociedades sustentáveis: análise da articulação de processos educativos formais e não formais como estratégias para a gestão do desenvolvimento local sustentável. Revista da FAEEBA - Educação $e$ Contemporaneidade, Salvador. v.16, n.28, p. 113-119, jul./dez., 2007.

NUNES, Eduardo José Fernandes; MUTIM, Avelar Luiz Bastos; COSTA, Aline Oliveira. Estado da arte em educação ambiental nas regiões Norte e Nordeste do Brasil: análise dos trabalhos apresentados no GT 22 Educação Ambiental do EPENN (2005-2013). In: GOMES, Alfredo Macedo; LEAL, Telma Ferraz. Pesquisa em educação nas regiões Norte e Nordeste: balanço e perspectivas. Recife: Editora UFPE, 2014. p.459 - 475.

SAITO, Carlos Hiroo. Política nacional de educação ambiental e construção da cidadania: desafios contemporâneos. In. RUSCHEINSKY, Aloísio. Educação ambiental: abordagens múltiplas. Porto Alegre: Artmed, 2002.

SILVA, Francisca de Paula Santos da; DÉJARDIN, Isabelle Pedreira. Educação numa perspectiva da sustentabilidade: diálogo entre saberes. In: GURGEL, Paulo R. H; SANTOS, Wilson N. (Orgs). Saberes plurais, difusão do conhecimento e práxis pedagógica. Salvador: EDUFBA, 2011. p. 163 - 178.

SODRÉ, Maria Lúcia da Silva. Às margens do Velho Chico: o projeto inconcluso do INCRA e suas consequências para o modo de vida das famílias ribeirinhas assentadas no PAE-SF. 2008, 309 f. Tese (Doutorado em Sociologia). Centro de Filosofia e Ciências Humanas - Universidade Federal de Pernambuco. Recife.

WALDMAN, Maurício. Ecologia e lutas sociais no Brasil. 5 ed. São Paulo: Contexto, 2001. 